\title{
2D Analysis of Gold Weight Implantation Surgery Results in Paralytic Lagophthalmos
}

\author{
(D) Kubra Serefoğlu Cabuk, ${ }^{1}$ (D) Gamze Ozturk Karabulut,, ${ }^{1}$ (D) Korhan Fazil,, \\ (1) Senay Asik Nacaroglu, ${ }^{1}$ (1) Zehra Karaagac Gunaydin, ${ }^{2}$ () Muhittin Taskapili1 \\ ${ }^{1}$ Department of Ophthalmology, University of Health Sciences, Beyoglu Eye Training and Research Hospital, Istanbul, Turkey \\ ${ }^{2}$ Department of Ophthalmology, Dunyagoz Hospital, Istanbul, Turkey
}

\begin{abstract}
Objectives: Gold weight implantation in the upper eyelid is a frequently performed treatment for paralytic lagophthalmos to prevent corneal exposure. A margin reflex distance of -I and -2 (MRDI, MRD2), the palpebral fissure height (PFH), and the vertical lagophthalmos (LV) are I-dimensional (ID) measurements used in follow-up. Because the exposure area is 2-dimensional (2D), this study was designed to investigate the results using both ID and 2D analysis.

Methods: Ten patients who underwent pretarsal suborbicularis oculi gold weight implantation were included in the study. Photographs were taken with a digital camera and the images were analyzed using Image software (US National Institutes of Health, Bethesda, MD, USA). The lagophthalmos area (LA) and ocular surface area (OSA) were measured in 2D in addition to the MRDI, MRD2, PFH, LV. Preoperative and postoperative values were compared using the Wilcoxon signed-rank test. Associations between parameters were evaluated using Spearman's correlation analysis.

Results: The mean age of the patients ( 7 male, 3 female) was 39.6 16.4 years (range: 14-60 years). The mean implant weight was $1.46 \mathrm{~g}(0.8-1.6 \mathrm{~g})$. There were significant reductions in the MRDI, MRD2, PFH, OSA, LV, and LA values after surgery $(p<0.05)$. The weight of the gold implant had a strong correlation with the PFH, OSA, MRDI, and MRD2, but not the LV or LA, preoperatively. The OSA was strongly correlated with the MRDI, PFH, and the implant weight, but not the MRD2. The LA was strongly correlated with the LV, preoperatively. In the postoperative period, the OSA was strongly correlated with the PFH and the MRD2 but not the MRDI, while the LA was strongly correlated with the LV, MRDI, and the PFH.

Conclusion: It is easy to obtain 2D measurements using digital image analysis software, and they proved to be accurate and correlated strongly with ID measurements. The OSA and LA measurements were significantly lower following upper eyelid gold weight implantation. The PFH and LV were compatible with the OSA and LA, preoperatively.

Keywords: Gold weight, image analysis, ImageJ, paralytic lagophthalmos
\end{abstract}

\section{Introduction}

Complications ranging from mild punctate epitheliopathy to refractory corneal ulcers, keratitis, corneal scars, and even perforation may occur in the case of lagophthalmos after facial palsy. To prevent these sight-threatening consequences, it is crucial to manage paralytic lagophthalmos from early-onset. The main aim of the therapy is to overcome lagophthalmos and restore ocular surface area (OSA) moisture (I). Ocu-

How to cite this article: Serefoğlu Cabuk K, Ozturk Karabulut G, Fazil K, Asik Nacaroglu S, Karaagac Gunaydin Z, Taskapili M. 2D Analysis of Gold Weight Implantation Surgery Results in Paralytic Lagophthalmos. Beyoglu Eye J 202I; 6(3): 200-205.

Address for correspondence: Kubra Serefoglu Cabuk MD. Saglik Bilimleri Universitesi, Beyoglu Goz Egitim ve Arastirma Hastanesi, Goz Hastaliklari Anabilim Dalı, Istanbul, Turkey

Phone: +90212 2515900 E-mail: drqubra@gmail.com

Submitted Date: February 11, 2021 Accepted Date: April 20, 2021 Available Online Date: September 27, 2021

${ }^{\oplus}$ Copyright 2021 by Beyoglu Eye Training and Research Hospital - Available online at www.beyoglueye.com

OPEN ACCESS This work is licensed under a Creative Commons Attribution-NonCommercial-ShareAlike 4.0 International License. 
lar lubricants, nightly eyelid taping, temporary tarsorrhaphy, mullerectomy, levator muscle lengthening, lower eyelid tightening, suborbicularis oculi fat pad lifting, midface lifting, temporalis muscle transfer, upper eyelid hyaluronic acid injection and gold weight implantation are the choices of treatments (2-10). The treatment strategy is decided with regards to the severity of corneal disease and predicted facial palsy recovery time (I).

Upper eyelid pretarsal gold weight implantation is a frequently preferred treatment because of its effectiveness and reversibility $(3,4)$. The margin reflex distance I and 2 (MRD I and MRD2), palpebral fissure height (PFH), the amount of vertical lagophthalmos (LV) are the ID measurements used in the follow-up. We could not find a study presenting the upper eyelid gold weight results in 2D.

Because the exposure in lagophthalmos is $2 \mathrm{D}$, we aimed to measure the areas together with the vertical distances by an image analysis software and investigated the correlation between them.

\section{Methods}

The files and photos of the patients who underwent upper eyelid gold weight implantation for paralytic lagophthalmos between January 2017 and July 2019 in a tertiary care hospital were included in the study. Written informed consent was obtained from all patients. Patients lacking pre or post-operative photos and/or inadequate file content excluded from the study. Ethical approval was received from the Clinical Ethical Committee of the University of Health Sciences Haseki Training and Research Hospital (date: 21.10.2020, no: 2020-18I). The study was conducted following the Declaration of Helsinki. Patients lacking photographic data, having lower eyelid surgery simultaneously with gold weight implantation were excluded from the study.

All of the patients underwent a full ophthalmic examination. Routine eyelid measurements including MRDI, MRD2, $\mathrm{LV}$ were noted on the file. Golden weight sizer plaques were attached on the central I/3 pretarsal skin by double-sided

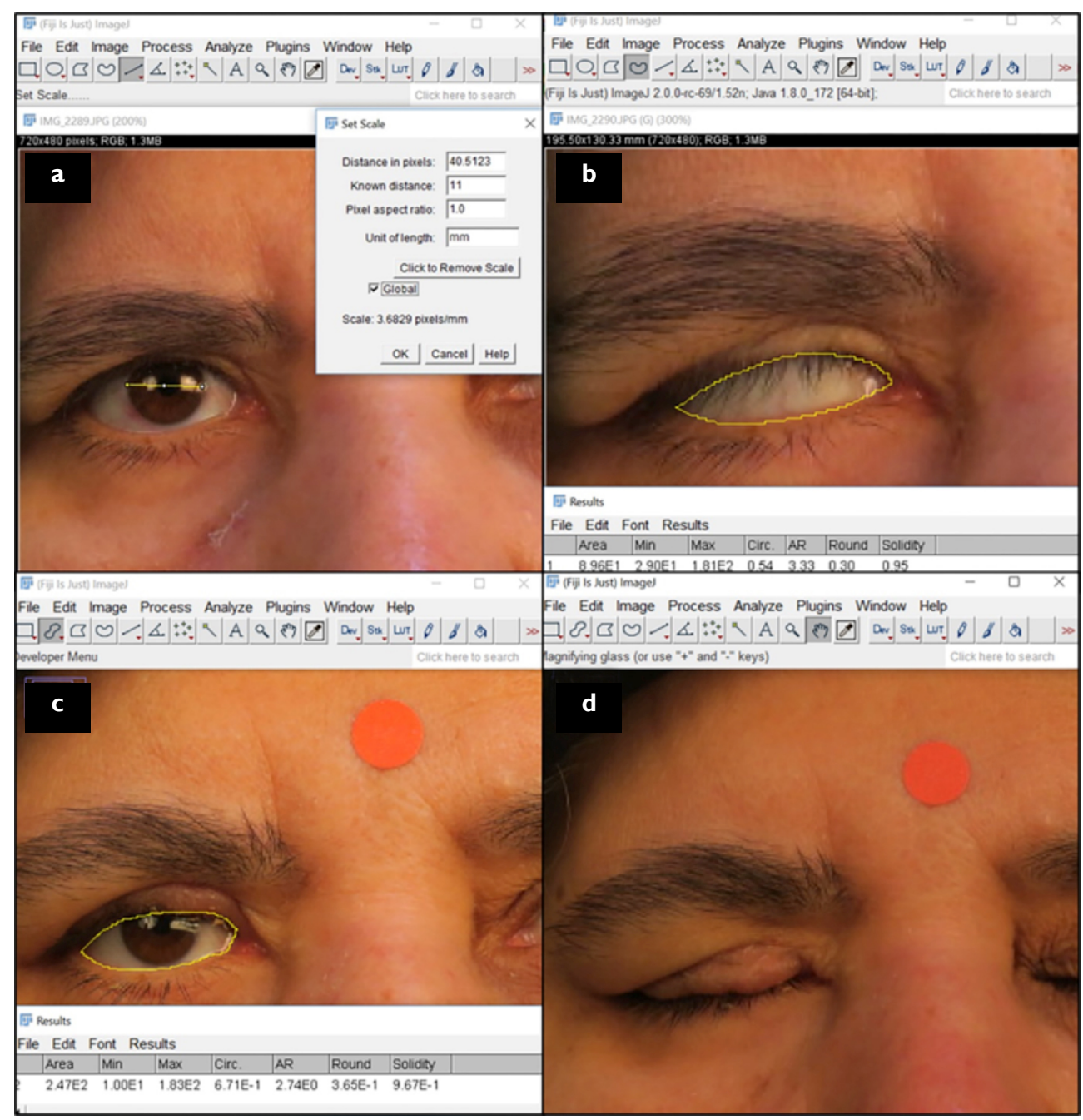

Figure I. (a) Calibration acoording to radius of the iris. (b) Measuring the area of lagophthamos in preoperative eyelid closure. (c) Measuring the ocular surface area. (d) Postoperative eyelid closure. 
tape. The weight causing minimal or no ptosis while reducing the lagophthalmos between $2 \mathrm{~mm}$ and $4 \mathrm{~mm}$ was chosen.

After a $10 \mathrm{~mm}$ sticker was attached to the glabella, photographs were taken by a digital camera (Canon G3X, Canon Inc., Tokyo, Japan) in the same lightening condition of the photo-room facing the camera, and chin-up while detecting lagophthalmos. Images were transferred to the computer. The setting scale was done using a $10 \mathrm{~mm}$ glabellar sticker. Iris diameter of new photos measured and used as a caliper for the earlier photos without a sticker of the same patient. The MRDI and MRD2, PFH, and the amount of LV is measured linearly, area of lagophthalmos (LA) and ocular surface (OSA) are measured 2D by ImageJ (Fig. I). All measurements were repeated three times by the same doctor. Manual measurements were also recorded in pre-and post-operative visits and compared with digital equivalents.

The implants were made up of $99.9 \%$ pure gold in the shape of curved rectangular, fitting well on the tarsus with rounded corners and edges including three holes enabling suture pass. All of them were produced in the same center.

All of the surgeries performed by 2 surgeons under local anesthesia by the same technique. $20 \mathrm{mg} / \mathrm{ml}$ lidocaine hydroclorur and $0.0125 \mathrm{mg} / \mathrm{ml}$ epinephrine infiltrated after marking the incision site throughout the upper eyelid crease. Skin and pretarsal orbicularis oculi are incised and the pretarsal area was exposed until I-2 $\mathrm{mm}$ to the eyelash margin. Gold implants are fixed to the central tarsus by 6.0 vicryl. The incision was closed separately by 3 pieces of 6.0 vicryl suture to form lid crease then continuously by 6.0 polypropylene suture.

All statistical analyses were performed with SPSS v. 22.0 (SPSS Inc., Chicago, IL). Descriptive statistics included mean values \pm SD for normally distributed variables. Distributions of the variables were measured by Kolmogorov-Smirnov test. For quantitative analysis, Wilcoxon signed-rank test was used. Correlation between parameters was evaluated by Spearman's correlation analysis. A P -value below 0.05 was considered statistically significant.

\section{Results}

The mean age of 10 patients ( 7 male and 3 female) was $39.6 \pm 16.4$ years (range, 14-60 years). The mean follow-up period was I I 3 days (ranging from 93 to I 50 days). The mean implant weight was $1.46 \mathrm{~g}(0.8-1.6 \mathrm{~g})$. Etiologies of facial palsy were cranial tumor $(n=2)$, cerebellopontine angle tumor $(n=1)$, motor vehicle accident $(n=2)$, and Bell's palsy $(n=5)$. There were no intraoperative complications. Preoperative exposure keratopathies resolved in 2 weeks after surgery. Hyperemia and thickening of the skin were seen in 2 patients which were resolved using topical steroid ointments. Implant visibility occurred in I patient but neither surgical success nor patient satisfaction was effected so no additional surgery was needed. No extrusion was seen in any of the implants. Explantation was performed because of recovery in one patient after 2 years.

There was no significant difference between the manual and digital measurements of MRDI, MRD2, PFH, LV $(p>0.05)$

There were significant reductions in MRDI, PFH, lagophthalmos vertical, OSA, and lagophthalmos area 3 months after surgery (Table I).

Correlations between pre-and postoperative measurements are shown in Tables 2 and 3.

Preoperative LA was strongly correlated with preoperative $L V(r=0.99, p=0.00)$. Postoperative $L A$ was strongly correlated with postoperative LV $(r=0.98, p=0.00)$, MRD I $(r=0.84, p=0.009)$ and PFH $(r=0.78, p=0.009)$.

\section{Discussion}

Complications ranging from corneal punctate keratopathy to permanent corneal opacification and even spontaneous corneal perforation may be seen as a result of corneal exposure emerging from facial palsy (10). So from the early onset of paralytic lagophthalmos, it is very important to protect the ocular surface and restore lubrication $(I, 12)$. Nightly eyelid taping, temporary tarsorrhaphy and fillers are the reversible choices of treatment. Lid loading, mullerectomy, levator

Table I. Postoperative changes in the findings

\begin{tabular}{lccc} 
& Preoperative & Postoperative & P-values \\
\hline MRDI $(\mathrm{mm})$ & $4 \pm \mathrm{I}$ & $2.21 \pm 0.6^{*}$ & 0.012 \\
MRD2 $(\mathrm{mm})$ & $7.6 \pm \mathrm{I}$ & $7.6 \pm \mathrm{I}$ & 0.28 \\
Palpebral fissure height $(\mathrm{mm})$ & $11.6 \pm 1.7$ & $8.7 \pm 1.3^{*}$ & 0.012 \\
Palpebral fissure area $\left(\mathrm{mm}^{2}\right)$ & $203 \pm 36$ & $147.5 \pm 18.4^{*}$ & 0.012 \\
Lagophthalmos vertical $(\mathrm{mm})$ & $7,41 \pm 2.3$ & $2.3 \pm 1.7^{*}$ & 0.012 \\
Lagophthalmos area $\left(\mathrm{mm}^{2}\right)$ & $132.5 \pm 38.6$ & $33.2 \pm 29^{*}$ & 0.012
\end{tabular}

MRDI: Margin reflex distance I; MRD2: Margin reflex distance $2 .{ }^{*}<0.05$, statistically significant. 
Table 2. Preoperative correlation between measurements

\begin{tabular}{lcccccc} 
& & Weight & MRDI & MRD2 & PFH & PFA \\
\hline Weight $(\mathrm{gr})$ & $\mathrm{r}$ & $\mathrm{I}$ & $.724^{*}$ & $.78 \mathrm{I}^{*}$ & $.905^{* *}$ & $.732^{*}$ \\
& $\mathrm{P}$ & & .042 & .022 & .002 & .039 \\
MRDI $(\mathrm{mm})$ & $\mathrm{r}$ & $.724^{*}$ & $\mathrm{I}$ & .383 & $.83 \mathrm{I}^{*}$ & $.970^{* *}$ \\
& $\mathrm{P}$ & .042 & & .349 & .011 & .000 \\
MRD2 $(\mathrm{mm})$ & $\mathrm{r}$ & $.78 \mathrm{I}^{*}$ & .383 & $\mathrm{I}$ & $.832^{*}$ & .500 \\
& $\mathrm{P}$ & .022 & .349 & & .010 & .207 \\
PFH $(\mathrm{mm})$ & $\mathrm{r}$ & $.905^{* *}$ & $.83 \mathrm{I}^{*}$ & $.832^{*}$ & $\mathrm{I}$ & $.883^{* *}$ \\
& $\mathrm{P}$ & .002 & $.01 \mathrm{I}^{*}$ & .010 & & .004 \\
PFA $(\mathrm{mm} 2)$ & $\mathrm{r}$ & $.732^{*}$ & $.970^{* *}$ & .500 & $.883^{* *}$ & $\mathrm{I}$ \\
& $\mathrm{P}$ & .039 & .000 & .207 & .004 & \\
\hline
\end{tabular}

Spearman's correlation analysis, $r$ : correalation coefficient, ${ }^{* *} \mathrm{p}<0.00 \mathrm{I},{ }^{*} \mathrm{p}<0.05$. MRD: Margin reflex distance; $\mathrm{PFH}$ : Palpebral fissure height; PFA: Palpebral fissure area.

Table 3. Postoperative correlation between measurements

\begin{tabular}{lcccccc} 
& & Weight & MRDI & MRD2 & PFH & PFA \\
\hline Weight $(\mathrm{gr})$ & $\mathrm{r}$ & $\mathrm{I}$ & .369 & .683 & .650 & .703 \\
& $\mathrm{P}$ & & .368 & .062 & .081 & .052 \\
MRDI $(\mathrm{mm})$ & $\mathrm{r}$ & .369 & $\mathrm{I}$ & .415 & $.786^{*}$ & .624 \\
& $\mathrm{P}$ & .368 & & .307 & .021 & .098 \\
MRD2 $(\mathrm{mm})$ & $\mathrm{r}$ & .683 & .415 & $\mathrm{I}$ & $.889^{* *}$ & $.809^{*}$ \\
& $\mathrm{P}$ & .062 & .307 & & .003 & .015 \\
PFH $(\mathrm{mm})$ & $\mathrm{r}$ & .650 & $.786^{*}$ & $.889^{* *}$ & $\mathrm{I}$ & $.864^{* *}$ \\
& $\mathrm{P}$ & $.08 \mathrm{O}$ & .021 & .003 & & .006 \\
PFA $(\mathrm{mm} 2)$ & $\mathrm{r}$ & .703 & .624 & $.809^{*}$ & $.864^{* *}$ & $\mathrm{I}$ \\
& $\mathrm{P}$ & .052 & .098 & .015 & .006 & \\
\hline
\end{tabular}

Spearman's correlation analysis, $r$ : correalation coefficient, ${ }^{* *} p<0.00$ I, ${ }^{*} p<0.05$. MRD: Margin reflex distance; PFH: Palpebral fissure height; PFA: Palpebral fissure area.

muscle lengthening, lateral tarsal strip, suborbicularis oculi fat lift, midface lift, temporalis muscle transfer are mostly saved for long-lasting cases (I).

Upper eyelid gold weight implantation in the case of paralytic lagophthalmos is a frequently preferred surgery because of its effectiveness and reversibility $(4,12)$. The weight enhances gravity to close the upper eyelid (13). Foreign body reaction, allergic reaction, permanent redness, astigmatism, entropion, eyelash ptosis, ptosis, inadequate improvement, implant visibility, bulging or migration of the implant and implant extrusion are the main complications (14). Even if it is shown in some studies that platinum implantation and/or post septal implantation lessen most of these side effects, pretarsal gold weight implantation still keeps its popularity (I5).
In 1983 Rolando et al. described the measurement of the OSA using an enlarged photography image and calculator plotter (16). They presented an equation of "OSA $\left(\mathrm{cm}^{2}\right)=$ $0.28 \times$ PFH $(\mathrm{cm})-0.44$ ". Sotoyama et al. accepted the OSA as a part of the spheric area and used the equation of "OSA $\left(\mathrm{cm}^{2}\right)=3.05 \times \mathrm{PFH}(\mathrm{cm})-0.39$ " to estimate it (17). He described the OSA in a nice schematic diagram. However, periorbital features vary according to age, sex and ethnicity so these equations are inadequate to measure the $2 \mathrm{D}$ data precisely (I8-2I).

With the development of digital imaging technology and analyzing software, measuring throughout the images became more accurately and quantitatively. ImageJ is a free and reliable digital image analysis software available from the $\mathrm{Na}$ tional Institute of Health, Bethesda, Maryland, USA (http:// 
rsb.info.nih.gov/ij). It has been used in several disciplines successfully (22-24). In periorbital regions, Cruz et al. used ImageJ in 1998 to assess upper eyelid contours quantitatively in Graves and congenital blepharoptosis (25). Nunes et al. found no significant difference between measurements done manually and digitally and thus concluded that results obtained by photogrammetry of digital images are as reliable as a direct measurement (26). In our study, there was no significant difference in manual and digital measurements, also.

Rajyalakshhmi et al. put forth that periorbital biometric measurements using Image software were reproducible and repeatable (27). Zheng et al. exposed eyelid features and eyebrow position following $\mathrm{CO}_{2}$ Laser-assisted blepharoptosis surgery by digital image analysis more accurately and quantitatively and underlined the increase in OSA in addition to MRDI after surgery (28). Tsai et al. presented an increase in OSA and improvement in ocular asymmetry after double eyelid blepharoplasty using ImageJ (29).

In paralytic lagophthalmos, Mancini et al. used ImageJ to present the effect of hyaluronic acid use in the upper eyelid (2). They showed a significant improvement in lagophthalmos but only by the ID measurements. Significant improvement in lagophthalmos were evident in our study too.

Success criteria after upper eyelid gold weight implantation were defined as a minimum $50 \%$ reduction in lagophthalmos or to minimize LV between $2 \mathrm{~mm}$ and $4 \mathrm{~mm}$ without inducing $>2 \mathrm{~mm}$ ptosis (30-32). Postoperative LV was $2.3 \pm 1.7 \mathrm{~mm}$ in our study and reduction in LV and LA were $>50 \%$ except for one patient (54\%) despite $1.6 \mathrm{~g}$ weight. No increment in the gold weight has been performed because of adequate symptom relief.

Ptosis was evident in all of our cases similar to the literature (I2). In the consequent of this, MRDI, PFH, and OSA reduced significantly after surgery. Although ptosis was $>2$ $\mathrm{mm}$ in 2 patients, we did not reduce the weights of them because of remaining corneal exposure in one of them and patient desire in the other.

The weight of the golden implant was most strongly correlated with preoperative PFH, OSA, MRDI, and MRD2 but not with LV or lagophthalmos area.

Although preoperative weight decision is made considering LV and ptosis, we did not find a correlation between them $(3 \mathrm{I}, 33)$. This may be because of the lower case number.

OSA was most strongly correlated with MRDI, than with PFH and gold weight heaviness but not with MRD2 preoperatively. The upper eyelid curvature is steeper than the lower eyelid so mainly the upper eyelid area determines the OSA preoperatively. MRDI overlaps the upper eyelid radius, therefore OSA is most correlated with MRDI (I7).

Postoperative OSA was strongly correlated with post- operative PFH and MRD2 but not with MRDI. Because of postoperative ptosis, the curvature of the upper eyelid gets shorter, then PFH mainly consists of MRD2. PFH should be used either pre or postoperatively to estimate OSA. However, to differentiate upper and lower eyelid behaviors, it is meaningful to use MRDI and MRD2 in clinical practice.

The restrictions of this study are lower case numbers. Studies with higher case numbers with preoperative weight decisions by digital photograph analysis would further lighten the exact equations between weight and the $2 \mathrm{D}$ measurements.

Upper eyelid gold weight implantation is a very effective surgery in the treatment of paralytic lagophthalmos. Digital image analysis guides the oculoplastic surgeon to see the improvement after periocular surgeries while delivering the advantage of talking about the results with the patient. OSA and LA significantly reduced after upper eyelid gold weight implantation. PFH and LV were found to be compatible with OSA and LA, respectively, perioperatively.

\section{Disclosures}

Ethics Committee Approval: University of Health Sciences Haseki Training and Research Hospital Clinical Research Ethics Committee, protocol number: 2020-181, Date: 21/10/2020.

Peer-review: Externally peer-reviewed.

Conflict of Interest: None declared.

Authorship Contributions: Involved in design and conduct of the study (KSC, GOK); preparation and review of the study (KSC, GOK, KF, SAN, MT); data collection (KSC, SAN, ZKG, MT); and statistical analysis (KSC, SAN).

\section{References}

I. Vásquez LM, Medel R. Lagophthalmos after facial palsy: current therapeutic options. Ophthalmic Res 2014;52:165-9. [CrossRef]

2. Mancini R, Taban M, Lowinger A, Pariseau B, Leyngold AR, Anderson RL. Use of hyaluronic acid gel in the management of paralytic lagophthalmos: the hyaluronic acid gel 'gold weight'. Ophthal Plast Reconstr Surg 2009;25:23-6. [CrossRef]

3. Rofagha S, Seiff SR. Long-term results for the use of gold eyelid load weights in the management of facial paralysis. Plast Reconstr Surg 2010;125:142-9. [CrossRef]

4. Hassan AS, Frueh BR, Elner VM. Müllerectomy for upper eyelid retraction and lagophthalmos due to facial nerve palsy. Arch Ophthalmol 2005; | 23: | 22I-5. [CrossRef]

5. Guillou-Jamard MR, Labbé D, Bardot J, Benateau H. Paul Tessier's technique in the treatment of paralytic lagophthalmos by lengthening of the levator muscle: evaluation of 29 cases. Ann Plast Surg 201 I;67:S3I-5. [CrossRef]

6. Egemen O, Ozkaya O, Uscetin I, Akan M. Covering the gold weight with fascia lata graft in paralytic lagophthalmos patients. Br J Oral Maxillofac Surg 2012;50:369-72. [CrossRef]

7. Silver AL, Lindsay RW, Cheney ML, Hadlock TA. Thin-profile 
platinum eyelid weighting: a superior option in the paralyzed eye. Plast Reconstr Surg 2009; 123:1697-703. [CrossRef]

8. Ben Simon GJ, Lee S, Schwarcz RM, McCann JD, Goldberg RA. Subperiosteal midface lift with or without a hard palate mucosal graft for correction of lower eyelid retraction. Ophthalmology 2006; I I 3:1869-73. [CrossRef]

9. Patel MP, Shapiro MD, Spinelli HM. Combined hard palate spacer graft, midface suspension, and lateral canthoplasty for lower eyelid retraction: a tripartite approach. Plast Reconstr Surg 2005; I 15:2105-14; discussion 21 15-7. [CrossRef]

10. Rozen S, Lehrman C. Upper eyelid postseptal weight placement for treatment of paralytic lagophthalmos. Plast Reconstr Surg 2013;131:1253-65. [CrossRef]

II. Gilbard SM, Daspit CP. Reanimation of the paretic eyelid using gold weight implantation. A new approach and prospective evaluation. Ophthalmic Plast Reconstr Surg 1991;7:93-103.

12. Pausch NC, Kuhnt CP, Halama D. Upper-eyelid weight implants for patients with lagophthalmos-comparison of rigid and flexible implants. J Craniomaxillofac Surg 2018;46:1843-9.

13. Baheerathan N, Ethunandan M, llankovan V. Gold weight implants in the management of paralytic lagophthalmos. Int J Oral Maxillofac Surg 2009;38:632-6. [CrossRef]

14. Rolando M, Refojo MF. Tear evaporimeter for measuring water evaporation rate from the tear film under controlled conditions in humans. Exp Eye Res 1983;36:25-33. [CrossRef]

15. Sotoyama M, Jonai H, Saito S, Villanueva MB. Analysis of ocular surface area for comfortable VDT workstation layout. Ergonomics 1996;39:877-84. [CrossRef]

16. Oztürk F, Yavas G, Inan UU. Normal periocular anthropometric measurements in the Turkish population. Ophthalmic Epidemiol 2006; 13:145-9. [CrossRef]

17. Vasanthakumar P, Kumar P, Rao M. Anthropometric analysis of palpebral fissure dimensions and its position in South Indian ethnic adults. Oman Med J 2013;28:26-32. [CrossRef]

18. Kunjur J, Sabesan T, llankovan V. Anthropometric analysis of eyebrows and eyelids: an inter-racial study. $\mathrm{Br}$ J Oral Maxillofac Surg 2006;44:89-93. [CrossRef]

19. Park DH, Choi WS, Yoon SH, Song CH. Anthropometry of asian eyelids by age. Plast Reconstr Surg 2008; I21:|405-13.

20. Dal Yontem F, Kim SH, Ding Z, Grimm E, Ekmekcioglu S, Akcakaya $\mathrm{H}$. Mitochondrial dynamic alterations regulate melanoma cell progression. J Cell Biochem 2018;120:2098-108.
2I. Erguvan O, Louveaux M, Hamant O, Verger S. ImageJ SurfCut: a user-friendly pipeline for high-throughput extraction of cell contours from 3D image stacks. BMC Biol 2019;17:38.

22. Doughty MJ. On the use of NIH image J for objective assessment of conjunctival cell and nucleus dimensions of impression cytology samples. Eye Contact Lens 20I I;37:50-6. [CrossRef]

23. Cruz AA, Coelho RP, Bacceaga A, Lucchezi MC, Souza AD, Ruiz EE. Digital image processing measurement of the upper eyelid contour in graves disease and congenital blepharoptosis. Ophthalmology 1998; 105:913-8. [CrossRef]

24. Nunes TP, Oliveira TF, Matayoshi S. A comparative study of the manual and digital measurements of the palpebral fissure. J Fr Ophtalmol 1995; |8:286-91.

25. Koushan K, Skibell BC, Harvey JT, Jankowski HK, Deangelis DD, Oestreicher JH. Digital photography as a novel technique of measuring ocular surface dimensions. Orbit 2008;27:259-65.

26. Rajyalakshmi R, Prakash WD, Ali MJ, Naik MN. Periorbital biometric measurements using imagej software: standardisation of technique and assessment of intra- and interobserver variability. J Cutan Aesthet Surg 2017; 10:130-5. [CrossRef]

27. Zheng $X$, Kakizaki H, Goto T, Shiraishi A. Digital analysis of eyelid features and eyebrow position following $\mathrm{CO} 2$ laser-assisted blepharoptosis surgery. Plast Reconstr Surg Glob Open 2016;4:el063. [CrossRef]

28. Tsai PY, Wu YC, Lai CH, Huang SH, Lai YW, Lai CS. Ocular surface area changes after double eyelidplasty. J Plast Reconstr Aesthet Surg 2012;65:el4I-5. [CrossRef]

29. Aggarwal E, Naik MN, Honavar SG. Effectiveness of the gold weight trial procedure in predicting the ideal weight for lid loading in facial palsy: a prospective study. Am J Ophthalmol 2007; |43:1009-12. [CrossRef]

30. Manktelow RT. Use of gold weight for lagophthalmos. Oper Tech Plast Reconstr Surg 1999;108:1539-43. [CrossRef]

31. Hontanilla B. Weight measurement of upper eyelid gold implants for lagophthalmos in facial paralysis. Plast Reconstr Surg 2001;108:1539-43.

32. Jobe RP. A technique for lid loading in the management of the lagophthalmos of facial palsy. Plast Reconstr Surg 1974;53:29_ 32. [CrossRef]

33. Chapman P, Lamberty BG. Results of upper lid loading in the treatment of lagophthalmos caused by facial palsy $\mathrm{Br} J$ Plast Surg. 1988;41:369-72. [CrossRef] 